\title{
47. Prolonged Cerebral Circuratory Interruption under Extremely Profounded Regional Hypothermia by means of Isolated Cerebral Vascular Irrigation
}

\author{
T. Kudo, M.D., K. Masuda, M.D., S. Fukuda, M.D., N. Yoshir, M.D., \\ H. Hirai, M.D., I. Katayama, M.D., I. Ochi, M.D., S. Toya, M.D. \\ S. ShimizU, M.D., M. Tanaka, M.D. and M. Hattori, M.D. \\ Department of Surgery Neuro-surgical Division, School of Medicine, \\ Keio University \\ M. Yamamoto, M.D. and H. Tawara, M.D. \\ Department of Anesthesiology, School of Medicine, \\ Keio University
}

48 adult dogs are used for this experimental study. At first surface cooling is used until body temperature falls to $30^{\circ} \mathrm{C}$. Cerebral irrigation by means of about $0^{\circ} \mathrm{C}$ harmless isotonic solution (PVP Ringer's solution or PVP amino-acid solution) is done from one side of internal carotid artery to opposite side of external jugular vein with $130 \mathrm{mmHg}$ pressure fluid level. Main vessels are all clamped and the connection of cerebral and body circulation is interrupted completely as possible. In this manner within 15 minutes brain temperature goes down to $6-7^{\circ} \mathrm{C}$. 1-1 $\frac{1}{2}$ hours after circuratory arrest all clamps of neck vessels are removed and cerebral blood flow is restarted. Cerebral temperature begins to rise gradually and surface warming is applied for complete returning to normal body temperature. In lapse of 5-6 hours after rewarming they become conscious and look around the surroundings and take a meal by their own accord.

This new technique is applied clinically-3 brain tumor cases are operated and 58 to 96 minutes cerebral circulatory arrest is done successfully. After rewarming these patients gain consciousness and obey simple command easily. No marked deficits of vitalities or mentalities are demonstrated. All cases are discharged uneventfully.

\section{Profounded Hypothermia with Use of Selective Brain Cooling}

\author{
Hajime Handa, Masayasu Matsushima, Tomio Ohta, \\ Minoru Aoyagi and Takuro TAKase \\ First Surgical Division, Kyoto University Medical Schol
}

We are reporting the experimental studies on selective brain cooling in dogs, 
in which polarographic measurements are used as an indicator of the cerebral anoxia, and hematologic changes are searched for with reference to the combination of profound hypothermia and extracorporeal circulation.

Along with these works, we had recently an opportunity to use the selective brain cooling in a human case. The patient was 27 years old man, who had been suffering from bifrontal glioblastoma multiforme. The temperature of his brain was lowered down to $16.5^{\circ} \mathrm{C}$ within 30 minutes. Thereafter flow rate of extracorporeal circulation was reduced from $500 \mathrm{cc} / \mathrm{min}$. to $100 \mathrm{cc} / \mathrm{min}$., which was maintained throughout the procedure for four hours. During the procedure, however, the arterial inflow to the brain was completely occluded in three times, 20 minutes, 20 minutes and ten minutes, respectively. His rectal temperature was maintained above $31.5^{\circ} \mathrm{C}$ and no cardiac arrhythmia was found in E.C.G. It was surprising that the operative field was almost bloodless and no troubles were encountered. Soon after the operation, he recovered his consciousness.

\title{
48. Hypothermia in Head Injuries
}

\author{
Hiroshi Toyoshima, Kintomo Takakura, Hiroshi Miyake, Isao \\ Hayakawa, Eiichi Yamamoto, Shojiro Chiba, Masumi Yoshioka, \\ Norio Nakamura, Junichi Shikata and Keiji Sano \\ 1st Surg. Dept., University of Tokyo
}

\section{Three Cured Cases of Severe Head Injuries with Treatment of Surgery and Hibernation}

\author{
Shigenobu Takayama, M.D. and Shoei Tobe, M.D. \\ Surgical Department, The First National Hospital, Tokyo
}

In this paper, we discussed surgical treatment and artificial hibernation which cured 3 severe head injury cases.

Three cases were as follows: 1) K.M., female aged 37, had coma, fixed dilated pupils on both sides and her body temperature of $39^{\circ} \mathrm{C} 11$ hours after head injury. Also she had melena on 15 th posttraumatic day which suggested as having Cushing's ulcer on her stomach. 2) T.S., male aged 20, had an opened depressed fracture in the right frontal region which was suppurated later. On 8th posttraumatic day he became unconscious and had a fixed dilated pupil on the right. Also his body temperature had risen to $39.5^{\circ} \mathrm{C}$ on that day. 3) T. N., male aged 